\title{
Impact of Extracorporeal Stent Placement during Laparoscopic Pyeloplasty on Operative Duration
}

\author{
Hasan Demirkan, ${ }^{1}$ (i) Kaya Horasanli² \\ 'Department of Pediatric Urology, University of Health Sciences Turkey, Kanuni Sultan Suleyman Training and Research Hospital, \\ Istanbul, Turkey \\ ${ }^{2}$ Department of Pediatric Urology, University of Health Sciences Turkey, Sisli Etfal Training and Research Hospital, Istanbul, Turkey
}

\begin{abstract}
Objectives: Ureteric stent insertion during laparoscopic pyeloplasty is the common practice for the reconstruction of ureteropelvic junction obstruction (UPJO). The long and hard learning curve of the method leads still controversy among surgeons. The utility of extracorporeal stent insertion in terms of shortening the length of operation time will be discussed in this study.

Methods: A total of 36 children who underwent pyeloplasty for UPJO were evaluated retrospectively. Indications for pyeloplasty were: Obstruction findings in renal scintigraphy, progressive kidney function loss, increasing in anteroposterior pelvis diameter in renal ultrasonography, and current clinical symptoms (febrile urinary tract infection and flank pain). Extracorporeal stent insertion procedure was performed as the following order: Ureteropelvic area and ureter were visualized transperitoneal by three trochars, and UPJO was excised. Thereafter, the ureter is taken out of the skin from pelvic trochar entrance and is spatulated. JJ stent is placed into the ureter. Following this move, the ureter is taken into the intra-abdominal area and first ureteropelvic suture is performed intra-abdominally.

Results: Thirteen of patients were girls and 23 were boys. Open surgery was applied for 15 patients (Group 1) and laparoscopic pyeloplasty (Group 2) to 21 patients. In Group 2, JJ stent was placed intracorporeally for six patients (Group 2a) and extracorporeally for the other 15 patients (Group 2b). The average age in Group 1 was $49.2 \pm 52$ months; it was 86 \pm 29 months in Group 2a and $144 \pm 52$ months in Group $2 b$, and the significant difference was present $(p<0.001)$. There was statistically significant difference between Group 1 and Group 2 regarding with mean hospital stay (40 h in Group 1 and 42 h in Group 2; p=0.001). Post-operative JJ stent removal time was 58.8 days in Group 1 and 52.89 days in Group 2. In Group 2b patients, placing the stent extracorporeally took a significantly shorter operation time and the difference between the operation times of the groups (2a [192 min \pm 3.76 ] and $2 \mathrm{~b}[135 \mathrm{~min} \pm 2.6][\mathrm{p}<0.001])$ was statistically significant. No statistical difference was found between $\mathrm{Group} 1$ (9.87 $\pm 5.5 \mathrm{~mm}$ ) and Group $2(12.91 \pm 5.3 \mathrm{~mm})$ in terms of renal anteroposterior diameters in the control ultrasonographic evaluation at the postoperative $2^{\text {nd }}$ year $(p=0.23$ ). There was no difference between the two groups as a result of the evaluation of renal functions by scintigraphy at the post-operative $1^{\text {st }}$ year (Group 1: $3.95 \pm 2 \%$; and Group 2: $0.78 \pm 5.3 \%$ ).

Conclusion: According to the consequences in this study, extracorporeally ureteric stent insertion during laparoscopic pyeloplasty shortens the length of operation duration so that extracorporeal insertion might be preferred in cases where it is difficult to place the stent during laparoscopic pyeloplasty.
\end{abstract}

Keywords: Extracorporeal stent, laparoscopic pyeloplasty.

Please cite this article as "Demirkan H, Horasanli K. Impact of Extracorporeal Stent Placement during Laparoscopic Pyeloplasty on Operative Duration. Med Bull Sisli Etfal Hosp 2021;55(2):162-166".

Address for correspondence: Hasan Demirkan, MD. Saglik Bilimleri Universitesi, Kanuni Sultan Suleyman Egitim ve Arastirma Hastanesi, Cocuk Urolojisi Klinigi, Istanbul, Turkey

Phone: +90 5334221729 E-mail: drhdemirkan@gmail.com

Submitted Date: June 24, 2020 Accepted Date: September 17, 2020 Available Online Date: July 02, 2021

${ }^{\circ}$ Copyright 2021 by The Medical Bulletin of Sisli Etfal Hospital - Available online at www.sislietfaltip.org

OPEN ACCESS This is an open access article under the CC BY-NC license (http://creativecommons.org/licenses/by-nc/4.0/). 
In pediatric patients, ureteropelvic junction obstruction (UPJO) is a major reason for obstructive uropathy. ${ }^{[1]}$ To correct the defect, various treatment modalities include laparoscopic pyeloplasty, robot-assisted pyeloplasty, small-incision open retroperitoneal repairs, laparoendoscopic single-site pyeloplasty, and retroperitoneoscopic assisted pyeloplasty have been used in recent years. ${ }^{[2-5]}$ Among these, laparoscopic pyeloplasty is still considered the main surgical reconstruction method for minimally invasive approach in children ${ }^{[6-8]}$ During the operation, the common practice is to create an waterproof anastomosis, necessitating stent insertion. As a result of it has a long and hard learning curve, there is still controversy about the method of $\mathrm{JJ}$ stenting. Stent placement has been performed extracorporeally for several years, but in the literature, there are limited studies about this technique, and it is not statistically indicated that the technique shortens the operation time..$^{[9,10]}$

In the present study, we compared post-operative urinary system dilatation, operation duration, mercaptoacetyltriglycine-3 (MAG-3) findings for two distinct laparoscopic pyeloplasty techniques (intra and extracorporeal stent placing) and aimed to highlight extracorporeal stenting advantages. According to the best of our knowledge, this technique significantly shortens the operation time as never reported any other studies with statistical data in the literature in children.

\section{Methods}

This study is ethically approved by the authorities in our hospital ethical committee with a number of 2466 and the date August 20, 2019. Between 2014 and 2017, a total of 36 children who had UPJO diagnosis underwent pyeloplasty in pediatric urology clinic. These operations were performed by a single surgeon. Cases were followed up for 2 years after surgery and evaluated retrospectively in the present study.

Indications for pyeloplasty were poor drainage (time to reach the maximum of the curve or half clearance time $[T 1 / 2]>20 \mathrm{~min}$ ) or progressive kidney function loss or progressive increase in anteroposterior pelvis (AP) diameter and renal parenchyma thinning in renal ultrasonography or current clinical symptoms (febrile urinary tract infection and flank pain).

In this study age, operation techniques, operation duration, complications, post-operative JJ stent removing time, pre-operative-post-operative anteroposterior pelvic diameter, hydronephrosis degree, and renogram findings are evaluated.

Renal pelvis anteroposterior diameter and Society of Fetal Ultrasound's system were used for hydronephrosis grading, which included mild (Grade 1-2), moderate (Grade 3), and severe (Grade 4). UPJO with symptomatic stenosis or decreased kidney function was documented with MAG-3.

Dismembered pyeloplasty was performed for all 36 patients in this study. Fifteen of them were operated with open pyeloplasty including flank incision (Group 1) and 21 of them were operated with transperitoneal laparoscopic pyeloplasty (Group 2). In Group 2, JJ stent was placed intracorporeally for six patients (Group 2a) and after these patients, all new cases with a number of 15 , stent was handled extracorporeally (Group 2b). In extracorporeal method, ureteropelvic area was visualized transperitoneal by three trochar, UPJO was excised and ureter dissected. Thereafter, ureter is taken out of the skin from pelvic trochar entrance and is spatulated (Fig. 1). JJ stent is placed into the ureter (Fig. 2). Following this move, ureter is taken into the intra-abdominal area and first ureteropelvic suture is performed intra abdominally.

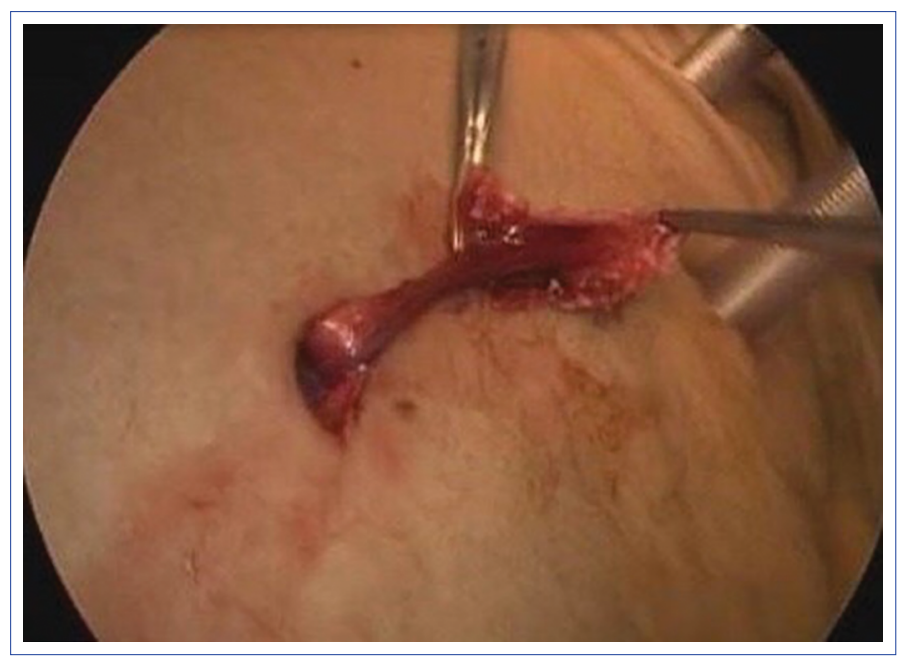

Figure 1. Extracorporeal spatulation.

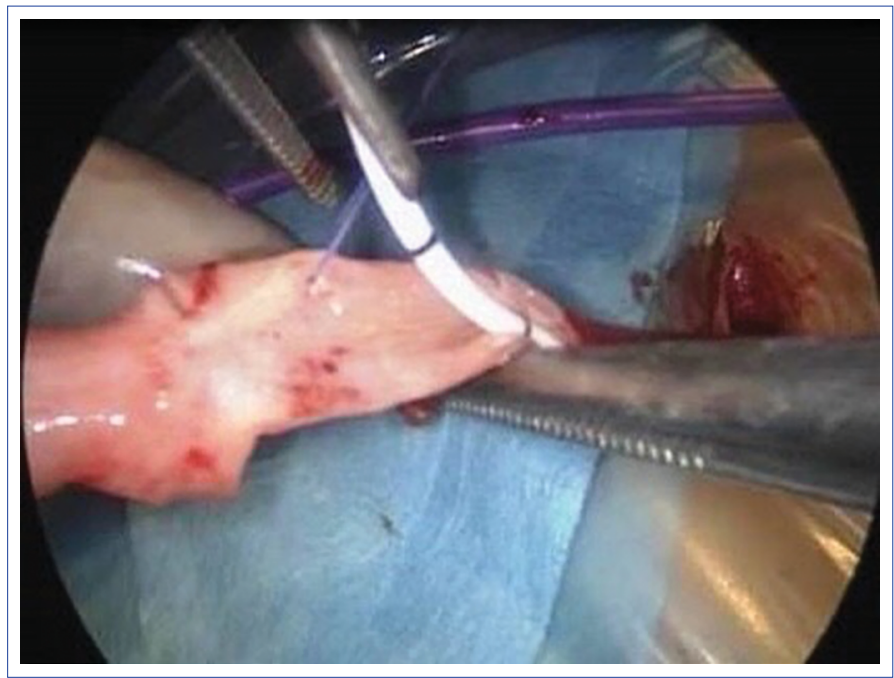

Figure 2. Extracorporeal stent insertion. 
The surgery success was defined as Grade 2 and lower grade hydronephrosis in ultrasonography and also detecting objectively in scintigraphy the improving of obstruction findings. All cases are evaluated with ultrasonography 1 month after the operation and with both ultrasonography and scintigraphy 6 month after the operation.

\section{Statistical Analysis}

The Statistical Package of the Social Science software 22.0 for Windows was used for the statistical analysis. Categorical variables are presented as number and percentage and numerical variables are presented as mean \pm standard deviation. Continuous variables that were not normally distributed (e.g., age) were compared using the Mann-Whitney U-test, while the others were compared using Student's t-tests. Categorical variables such as complications were compared using the Chi-squared test. Values of $p<0.05$ were considered statistically significant.

\section{Results}

Patient demographics are summarized in Table 1. Twenty patients had UPJO in the right kidney and 16 patients in the left kidney. Fifteen patients were treated with open pyeloplasty and 21 patients were treated with laparoscopic pyeloplasty. They were followed up at least years. Laparoscopic pyeloplasty performed patients were older and it was significantly different from the other group $(p<0.001)$. No complications (stent dislodgment, stent related urinary tract infection, and urinary leak) were observed. Operation time was $123.53 \mathrm{~min}$ in Group 1 and 151.85 min in Group 2. The time was significantly longer in Group 2 ( $p<0.001)$. Intraoperative data are summarized in Table 2.

In Group 1, mean pre-operative AP diameter was $33.2 \mathrm{~mm}$. It was found $20.96 \mathrm{~mm}$ on the $1^{\text {st }}$ post-operative month, $12.97 \mathrm{~mm}$ on the $1^{\text {st }}$ post-operative year, and $9.87 \mathrm{~mm}$ on the $2^{\text {nd }}$ post-operative year. In Group 2, mean AP diameter was detected $32.1 \mathrm{~mm}$ in pre-operative ultrasonography, $23.63 \mathrm{~mm}$ on the $1^{\text {st }}$ post-operative month, 16.88 at the $1^{\text {st }}$ post-operative year, and $12.91 \mathrm{~mm}$ at the $2^{\text {nd }}$ post-operative year (Table 3).
In Table 4, pre-operative and post-operative hydronephrosis degrees are reported. There was no significantly different result.

Six patients were treated with intracorporeal ureteric stenting and mean operation time was $192 \mathrm{~min}$. However, in 15 patients placing the stent extracorporeally had a shorter time as $135 \mathrm{~min}$. Duration of operation was greater in Group 2a. Between the two groups, operation times were significantly different (Table 5).

\section{Discussion}

Laparoscopic pyeloplasty has a difficult learning curve and important parts of the method are ureteric stent placing and spatulating. To make easier this process extracorporeally stent placement has been defined previously. ${ }^{[9,10]}$ However, its effect on operation time was not shown in any study, according to the best of our knowledge. In the present study, we suggest that this method shorten the opera-

Table 1. Demographic characteristics of the patients

\begin{tabular}{lccc}
\hline & $\begin{array}{c}\text { Group 1 } \\
\text { (n=15) }\end{array}$ & $\begin{array}{c}\text { Group 2 } \\
\text { (n=21) }\end{array}$ & p \\
\hline Age (month) & $49.2 \pm 52$ & $\begin{array}{c}128 \pm 53 \\
\text { (Group 2a: 86 }\end{array}$ & $<0.001^{*}$ \\
& & $\begin{array}{c}\text { (Group 2b: } 144 \pm 52) \\
14 / 7\end{array}$ & \\
Sex (Boys/girls) & $9 / 6$ & $14 / 7$ & 0.681 \\
$\begin{array}{l}\text { Laterality of UPJO } \\
\text { (Right/left) }\end{array}$ & $6 / 9$ & & 0.112 \\
\hline
\end{tabular}

UPJO: Ureteropelvic junction obstruction.

Table 2. Intraoperative data of cases

\begin{tabular}{lccc}
\hline & $\begin{array}{c}\text { Group 1 } \\
(\mathbf{n = 1 5 )}\end{array}$ & $\begin{array}{c}\text { Group 2 } \\
(\mathbf{n = 2 1 )}\end{array}$ & p \\
\hline Mean operative time (min) & 123.53 & 151.85 & $<0.001^{*}$ \\
Intraoperative complication (n) & 0 & 0 & \\
Postoperative complication (n) & 0 & 0 & \\
Length of hospital stay (hours) & 40 & 42 & 0.001 \\
Post-operative stent staying days & 58.8 & 52.89 & 0.178 \\
Success ratio \% & 100 & 100 & \\
\hline
\end{tabular}

Table 3. Summary of anteroposterior diameters and relative functions

\begin{tabular}{lccccc}
\hline & $\begin{array}{c}\text { Pre-operative AP } \\
\text { diameter }(\mathbf{m m})\end{array}$ & $\begin{array}{c}\text { Post-operative AP } \\
\text { diameter 1 } \\
\text { month }(\mathbf{m m})\end{array}$ & $\begin{array}{c}\text { Post-operative AP } \\
\text { diameter 1 year (mm) }\end{array}$ & $\begin{array}{c}\text { Post-operative AP } \\
\text { diameter 2 year (mm) }\end{array}$ & $\begin{array}{c}\text { Improving of } \\
\text { relative functions in } \\
\text { MAG-3 (\%) 1 year }\end{array}$ \\
\hline Group 1 & $33.2 \pm 12.4$ & $20.96 \pm 8.9$ & $12.97 \pm 5.1$ & $9.87 \pm 5.5$ & $3.95 \pm 2.1$ \\
Group 2 & $32.1 \pm 7.1$ & $23.63 \pm 7.39$ & $16.88 \pm 7.41$ & $12.91 \pm 5.3$ & $0.78 \pm 5.3$ \\
p & 0.967 & 0.354 & 0.127 & 0.235 & 0.703 \\
\hline
\end{tabular}

AP: Anteroposterior pelvis; MAG-3: Mercaptoacetyltriglycine-3. 
Table 4. Pre-operative and post-operative SFU degrees of patients

\begin{tabular}{|c|c|c|c|c|c|}
\hline & \multicolumn{2}{|c|}{ Grade 3} & \multicolumn{2}{|c|}{ Grade 4} & \multirow[t]{2}{*}{$\mathbf{p}$} \\
\hline & Group 1 & Group 2 & Group 1 & Group 2 & \\
\hline Pre-operative (n) & 7 & 9 & 8 & 10 & 0.747 \\
\hline $\begin{array}{l}\text { Post-operative } \\
\text { 1. month }(\mathrm{n})\end{array}$ & 4 & 13 & 0 & 0 & 0.096 \\
\hline $\begin{array}{l}\text { Post-operative } \\
\text { 1. year (n) }\end{array}$ & 1 & 6 & 0 & 0 & 0.372 \\
\hline $\begin{array}{l}\text { Postoperative } \\
\text { 2. year (n) }\end{array}$ & 0 & 1 & 0 & 0 & 0.887 \\
\hline
\end{tabular}

SFU: Society of fetal ultrasound.

Table 5. Data of laparoscopic pyeloplasty techniques

\begin{tabular}{lccc}
\hline & $\begin{array}{c}\text { Group 2a } \\
(\mathbf{n = 6})\end{array}$ & $\begin{array}{c}\text { Group 2b } \\
(\mathbf{n = 1 5 )}\end{array}$ & $\mathbf{p}$ \\
\hline Age (year) & $7.16 \pm 2.48$ & $12.06 \pm 4.33$ & 0.19 \\
Length of hospital stay (hours) & $41.16 \pm 1.16$ & $42.3 \pm 1.71$ & 0.13 \\
$\begin{array}{l}\text { Post-operative stent staying } \\
\text { period (month) }\end{array}$ & $3.5 \pm 1.04$ & $2.2 \pm 1.5$ & 0.15 \\
Mean operative time (min) & $192 \pm 3.76$ & $135 \pm 2.6$ & $<0.001$ \\
\hline
\end{tabular}

tion duration with statistically significant results.

The study by Kocherov et al. ${ }^{[9]}$ reported that the extracorporeal ureteric stenting is easy to learn, safe, and a practical method. They explained technical details of the method widely but did not mention about any statistical data of the operation duration. Nadu et al. ${ }^{[10]}$ described the method in detail; however, there is not any numerical information about the outcomes of the procedure and effect on the operation duration. In our study, mean operation time was found $192 \mathrm{~min}$ in intracorporeal stenting; otherwise, mean operation time was found $135 \mathrm{~min}$ in extracorporeal ureteric stenting. It showed us a shorter time and it was statistically different. This significant difference depends on insertion and spatulation of ureteric stent extracorporeally. Ureteral mobilization is discussed for reducing the ureteral blood supply in many studies. ${ }^{[9,11]}$ While performing the ureteral mobilization, we considered the possibility of decreased blood flow to ureter but we did not detect any problem and used this technique safely.

Long-term follow-up for the hydronephrosis of patients showed the success of operation for the treatment of UPJO. A study by Tanaka et al. ${ }^{[12]}$ showed that the success ratios of open and laparoscopic pyeloplasty are same for still existing hydronephrosis and this study is also correlated with these results. In the present study, laparoscopic pyeloplasty duration was longer than open surgery technique and Braga et al. ${ }^{[13]}$ had shown similar findings with us.

Polok and Apoznański ${ }^{[14]}$ assessed pre-operative and post-operative relative functions in 28 children in open surgery and found significant improvement. In this study, we also found improvement but no significant difference.

Study of Başataç et al. ${ }^{[15]}$ showed that relative functions improved significantly in the 2 years follow-up of the patients after open, laparoscopic, and robotic pyeloplasty. In the present study also, relative functions improved (0.78) for a 1 year follow but it was not a significant improvement. We revealed the benefits of this method defined previously, but the inadequate number of patients is the main limitation of this study.

\section{Conclusion}

Extracorporeal ureteric stent insertion and spatulation shorten the length of laparoscopic pyeloplasty duration. We showed shorten of the operation time significantly in this study. Fifteen patients had no complications after the operations and its effectiveness for treating UPJO makes us to use the laparoscopic pyeloplasty method practically and safely. More studies are needed to show the effectiveness of placing the JJ stent extracorporeally.

\section{Disclosures}

Ethics Committee Approval: The research protocol was approved by the authorities in Şişli Etfal Training and Research Hospital Ethics Committee (Date: 20.08.2019, Decision Number: 2466).

Peer-review: Externally peer-reviewed.

Conflict of Interest: None declared.

Financial Disclosure: The authors declare that this study received no financial support.

Authorship Contributions: Concept - H.D., K.H.; Design - H.D., K.H.; Supervision - H.D., K.H.; Fundings - H.D.; Materials - K.H.; Data collection \&/or processing - H.D.; Analysis and/or interpretation K.H.; Literature search - H.D.; Writing - K.H.; Critical review - H.D.

\section{References}

1. Mandhani A, Goel S, Bhandari M. Is antegrade stenting superior to retrograde stenting in laparoscopic pyeloplasty? J Urol 2004;171:1440-2. [CrossRef]

2. Chandrasekharam VV. Is retrograde stenting more reliable than antegrade stenting for pyeloplasty in infants and children? Urology 2005;66:1301-4. [CrossRef]

3. Arumainayagam N, Minervini A, Davenport K, Kumar V, Masieri L, Serni $S$, et al. Antegrade versus retrograde stenting in laparoscopic pyeloplasty. J Endourol 2008;22:671-4. [CrossRef]

4. Minervini A, Siena G, Masieri L, Lapini A, Serni S, Carini M. Antegrade stenting in laparoscopic pyeloplasty: feasibility of the technique and time required for stent insertion. Surg Endosc 2009;23:1831-4. [CrossRef]

5. van der Toorn F, van den Hoek J, Wolffenbuttel KP, Scheepe JR. 
Laparoscopic transperitoneal pyeloplasty in children from age of 3 years: our clinical outcomes compared with open surgery. J Pediatr Urol 2013;9:161-8. [CrossRef]

6. Moore K, Lorenzo AJ, Turner S, Bägli DJ, Pippi Salle JL, Farhat WA. Prospective cost analysis of laparoscopic vs. open pyeloplasty in children: Single centre contemporary evaluation comparing two procedures over a 1-year period. Can Urol Assoc J 2013;7:94-8.

7. Mei H, Pu J, Yang C, Zhang H, Zheng L, Tong Q. Laparoscopic versus open pyeloplasty for ureteropelvic junction obstruction in children: a systematic review and meta-analysis. J Endourol 2011;25:727-36. [CrossRef]

8. Cho SY, Kim IS, Lee SB, Choi H, Park K. Nature and fate of supranormal differential renal function: lessons from long-term follow-up after pyeloplasty. Urology 2013;81:163-7. [CrossRef]

9. Kocherov S, Lev G, Chertin L, Chertin B. Extracorporeal ureteric stenting for pediatric laparoscopic pyeloplasty. Eur J Pediatr Surg 2016;26:203-6. [CrossRef]

10. Nadu A, Mor Y, Ramon J. Direct extracorporeal ureteric stenting during laparoscopic pyeloplasty: a novel technique. BJU Int 2009;103:844-7. [CrossRef]

11. Kajbafzadeh AM, Zeinoddini A, Ebadi M, Heidari R, Tajalli A. Ex- ternal extension of double-J ureteral stent during pyeloplasty: inexpensive stent and non-cystoscopic removal. Int Urol Nephrol 2014;46:671-6. [CrossRef]

12. Tanaka ST, Grantham JA, Thomas JC, Adams MC, Brock JW $3^{\text {rd }}$, Pope JC $4^{\text {th }}$. A comparison of open vs laparoscopic pediatric pyeloplasty using the pediatric health information system database--do benefits of laparoscopic approach recede at younger ages? J Urol 2008;180:1479-85. [CrossRef]

13. Braga LH, Lorenzo AJ, Bägli DJ, Mahdi M, Salle JL, Khoury AE, et al. Comparison of flank, dorsal lumbotomy and laparoscopic approaches for dismembered pyeloplasty in children older than 3 years with ureteropelvic junction obstruction. J Urol 2010;183:306-11. [CrossRef]

14. Polok M, Apoznański W. Anderson-Hynes pyeloplasty in children - long-term outcomes, how long follow up is necessary? Cent European J Urol 2017;70:434-8.

15. Başataç C, Boylu U, Önol FF, Gümüş E. Comparison of surgical and functional outcomes of open, laparoscopic and robotic pyeloplasty for the treatment of ureteropelvic junction obstruction. Turk J Urol 2014;40:24-30. [CrossRef] 